\title{
Rheology of Diluted Heavy Crude Oil Saturated with Carbon Dioxide
}

Ruien Hu, John P. Crawshaw, J. P. Martin Trusler and Edo S. Boek*

Qatar Carbonates and Carbon Storage Research Centre (QCCSRC), Dept. of Chemical

Engineering, South Kensington Campus, Imperial College London, London SW7 2AZ, United

Kingdom.

KEYWORDS

Viscosity, Shear Rate, Heavy Crude Oil, Carbon Dioxide

\section{ABSTRACT}

The viscosity of heavy crude oils strongly affects their producibility and recovery from oil reservoirs. Thus, the viscosity of heavy crude oils with dissolved gases at different shear rates is valuable knowledge for heavy crude oil exploitation. However, most publications only present the viscosity measurements at one specific shear rate, and only few papers in the literature have reported the rheological measurements. In this study, viscosity measurements of $\mathrm{CO}_{2}$ saturated heavy crude oils were performed as a function of shear rate, at a temperature of $25^{\circ} \mathrm{C}$ and pressures up to 220 bar. The experimental apparatus is a unique circulation system which is able to measure the viscosity of $\mathrm{CO}_{2}$ saturated mixtures. A novel high pressure rheometer with a flow-through Couette geometry was developed to measure the viscosity at a range of shear rates. The 
experimental results show that the addition of $\mathrm{CO}_{2}$ to heavy crude oil at the given temperature and pressures reduces the viscosity significantly, but the pressure dependence of the mixture viscosity changes at the phase transition of the $\mathrm{CO}_{2}$ rich phase. A modified Arrhenius equation, accounting for the effect of $\mathrm{CO}_{2}$ composition on viscosity, is applied to correlate the viscosity data.

\section{Introduction}

Carbon dioxide $\left(\mathrm{CO}_{2}\right)$ is one of the most important greenhouse gases, due to large emissions to the atmosphere from chemical and transportation processes. It has a significant contribution to global warming and climate change [1]. Thus the technologies to reduce $\mathrm{CO}_{2}$ emission in the atmosphere have continuously drawn attention from governments and industry. Recently, the concept of carbon capture, utilization and storage (CCUS) has been developed, in order to provide an economically feasible strategy to reduce $\mathrm{CO}_{2}$ emissions in the short to medium term. Among all the technologies within the CCUS concept, $\mathrm{CO}_{2}$ flooding for Enhanced Oil Recovery (EOR) is one of the most promising ways to provide the opportunity to offset the cost of carbon storage in oil fields by improving oil recovery.

$\mathrm{CO}_{2}$ flooding requires a fundamental understanding of the thermodynamic and transport properties of $\mathrm{CO}_{2}$ and reservoir fluids under reservoir conditions. Measuring and predicting the transport properties of mixtures of reservoir fluids with $\mathrm{CO}_{2}$ under these extreme conditions is crucial for developing predictive models that can then be used to design the most cost-efficiency recovery strategy. The viscosity of the crude oil- $\mathrm{CO}_{2}$ mixture, which is a key parameter for mobility control, is fundamental for designing and managing the $\mathrm{CO}_{2}$ flooding productivity. This research project addresses the measurement the viscosity of crude oil- $\mathrm{CO}_{2}$ mixtures. However, apart from the effect of pressure and oil- $\mathrm{CO}_{2}$ composition on the mixture viscosity, this study also reveals the effect of 
shear rate. Given that $\mathrm{CO}_{2}$ dissolution in crude oil could give rise to asphaltene precipitation and deposition [2], the resulting mixture could have both solid and liquid phases present. From a rheological point of view, the precipitated solid particles could create a structural network, which would give rise to a shear rate dependence of the mixture viscosity - i.e. non-Newtonian behavior [3].

In the literature, many studies have focused on how the phase behavior and viscosity of crude oilgas mixtures are affected by temperature, pressure and gas composition. Kariznovi et al. give a good review about experimental set-ups and the measurements each can provide [4]. However, these early studies were not capable of detecting any non-Newtonian behavior of the fluid. Only recently, Behzadfar et al. have reported rheological measurements for $\mathrm{CO}_{2}$-bitumen mixtures [5]. These measurements were performed in a high pressure cell mounted on a rheometer. The $\mathrm{CO}_{2}$ saturation took place by diffusion with a gentle mixing process in the pressure cell. Complete saturation was indicated by stable viscosity and pressure measurements.

In this work, a circulation system has been built to saturate the crude oil with $\mathrm{CO}_{2}$. In this system, the mixing process and rheological measurement take place in two different units. The measurements were performed at $25^{\circ} \mathrm{C}$ and at various pressure and shear rate. The viscosity data were correlated with a modified Arrhenius equation.

\section{Experiments}

\section{Materials}

Pure squalane and squalane saturated with $\mathrm{CO}_{2}$ were used to test the system performance. The squalane sample used in the test was sourced from Sigma-Aldrich with purity of 99\%, and the 
$\mathrm{CO}_{2}$ (mole fraction purity $x \geq 0.99995$ ) was obtained from BOC. Both were used without further purification. Then two different diluted crude oil samples were studied. The diluted crude oils are mixtures of different amounts of toluene and a heavy crude oil sample provided by Shell, Netherlands, with an $n$-heptane asphaltene content of $18.8 \mathrm{wt} \%$. The density (at $15^{\circ} \mathrm{C}$ ) was measured to be $0.983 \mathrm{~g} / \mathrm{cm}^{3}$ and the kinematic viscosity $\left(\right.$ at $40^{\circ} \mathrm{C}$ ) was $20020 \mathrm{~mm}^{2} / \mathrm{s}$ [6]. Other key properties of the crude oil sample are listed in Table 1. As illustrated in Table 1 the viscosity of the crude oil is extremely high such that the gear pump in the circulation system was not powerful enough to circulate the crude oil even at elevated temperature. Therefore the crude oil was diluted by toluene to reduce its viscosity into the range that the circulation system could handle. The toluene used was sourced from Sigma-Aldrich with a purity of 99.8\%. The crude oil and toluene were used without further treatment. The compositions of the diluted crude oil samples are shown in Table 2.

\section{Viscosity Measurement}

The system designed and built to allow the viscosity measurement of gas-saturated crude oils is a circulation system, which contains four off-the-shelf pieces of equipment: a syringe pump, mixer, gear pump and rheometer, as shown in Scheme 1. The measurement procedure was as followings. First, the crude oil sample was loaded into the mixer and then the whole system was primed. The remaining volume in the system was evacuated for 30 minutes to remove air and the system brought to the set point temperature. $\mathrm{CO}_{2}$ was then introduced into the mixer via the syringe pump that controls the system pressure. Inside the mixer, a stirrer coupled with a rotating magnet was used to enhance the mixing between the crude oil and $\mathrm{CO}_{2}$. The mixture was circulated into the pressure cell of the rheometer by the gear pump. Once the pressure cell was completely full, the mixture was recycled back to the mixer and the circulation continued for more than 24 hours to 
ensure equilibrium. During the circulation, the stirrer was kept rotating in order to ensure the liquid had a uniform composition. The suction tube in the mixer removed fluid from close to the bottom of the mixer, sampling the liquid and not the vapor phase. After reaching equilibrium, the circulation was stopped and the viscosity measured in the rheometer. The saturation of the crude oil and $\mathrm{CO}_{2}$ was confirmed by no further reduction in pressure and viscosity was observed.

The mixer is a Parr Instruments 4651 reactor with a vessel volume of $250 \mathrm{ml}$, mounted on a Series 4923EE benchtop heater with a Series 4838 temperature controller. The mixer, manufactured in 316 stainless steel, is sealed with a PTFE flat gasket and split ring arrangement, operated at a maximum working pressure of 410 bar and up to $350{ }^{\circ} \mathrm{C}$. Stirring of the mixture is done by a stirring bar placed at the bottom of the vessel, which is driven by a rotating magnet set. The benchtop heater is modified to install the rotating magnet set via an electric motor, which provides stirring speeds adjustable from 0 to $1700 \mathrm{rpm}$.

The viscosity measurement was performed in a high-pressure cell mounted on the Anton Paar MCR301 rheometer. The high pressure cell had a concentric cylinder geometry with a $0.5 \mathrm{~mm}$ gap; it could be pressurized up to 400 bar and operated in a temperature range from 25 to $300{ }^{\circ} \mathrm{C}$. The sample volume was $18 \mathrm{ml}$. The design of the pressure cell allows high shear rates to be applied to viscoelastic samples without encountering problems such as the Weissenberg effect or the sample escaping from the gap [7]. Also, as the pressure cell is completely sealed and entirely flushed with the sample, there is no room for loading errors and the sample loading is repeatable. For every experiment an Air Check test was performed, in which the torque applied on the cylinder geometry in an empty cell is measured at the rotation speed of $0.3 \mathrm{~min}^{-1}$. Such torque is mainly caused by the friction on the sapphire bearings that contact with the cylinder geometry. The torque measured in Air Check was compared with the limits set by rheometer manufacturer to judge 
whether the pressure cell is working in good conditions. All the experiments that have performed showed a positive result in the Air Check. Also, the motor adjustment for the pressure cell was done manually. In the beginning of each experiment, the viscosity in an empty cell was measured at the interested shear rate values. Then, performed at the same share rates as in the empty cell, the viscosity measurements with samples was subtracted by that with empty cell, and the resulted viscosity values were the true measurement values. The uncertainty of the viscosity measurements was estimated by measuring the UKAS certified viscosity standards N35 and S600 (100\% hydrocarbons, from Paragon Scientific Ltd). The agreement with the standards in the certified temperature range $25-80{ }^{\circ} \mathrm{C}$ was better than $\pm 3.5 \%$. The repeatability of the rheological measurements was better than $1 \%$.

The gear pump circulating the fluid was a model GAH X21 suction shoe gear pump from Micropump. The pump was a rotating positive displacement pump which can be operated up to 345 bar and $120^{\circ} \mathrm{C}$. The main body of the gear pump was fabricated of stainless steel, while the gears and suction shoes were made of carbon. The pump was magnetically coupled to a drive motor.

\section{Measuring the mass of $\mathrm{CO}_{2}$ injected into the mixer}

Although the system was designed to measure the viscosity, using the syringe pump and the mixer the amount of $\mathrm{CO}_{2}$ injected can also be measured, which indicates the dissolution and phase behavior of the mixture.

Scheme 2 shows the measurement principle as follows. A known amount of crude oil was preloaded into the mixer. The air remaining in the system was then removed by evacuation, $\mathrm{CO}_{2}$ was introduced into the pump and the mixer, and the syringe pump was set to operate in constant 
pressure mode. At this stage, the $\mathrm{CO}_{2}$ had contacted the crude oil and would start to dissolve into it at a rate controlled by diffusion. However, the diffusion coefficient of $\mathrm{CO}_{2}$ in such crude oil is very small [8] and hence the rate of dissolution under diffusion control was very low and was assumed to be negligible. When the temperature and pressure reach the desired values, the stirrer was turned on to start the mixing. The now rapid dissolution of $\mathrm{CO}_{2}$ in the oil resulted in a volume change, $\Delta V$, in the syringe pump which was recorded. Given that the temperature and pressure inside the syringe pump were kept constant, the density of the $\mathrm{CO}_{2}, \rho_{\mathrm{CO}}$, inside the pump could be determined from an equation of state [9] and hence the mass of $\mathrm{CO}_{2}$ injected into the vessel could be determined as $m_{\mathrm{CO}_{2}}=\rho_{\mathrm{CO}_{2}} \Delta V$.

\section{Results and Discussion}

The viscosity measurement of pure squalane was performed at $25^{\circ} \mathrm{C}$ and $1 \mathrm{bar}$, at shear rates from 80 to 500 1/s. As shown in Figure 1, the viscosity of pure squalane is independent of the shear rate, behaving as a Newtonian fluid as expected. When $\mathrm{CO}_{2}$ was mixed with squalane at $25{ }^{\circ} \mathrm{C}$ and 4.3 bar, the saturated mixture had a lower viscosity than pure squalane, but also behaved as a Newtonian fluid. Compared to the literature values, the measurement errors for pure squalane and $\mathrm{CO}_{2}+$ squalane mixture are $2.4 \%$ and $3.8 \%$, respectively. The literature value of pure squalane viscosity was obtained from Ciotta et al. [10] while that of the $\mathrm{CO}_{2}+$ squalane mixture was calculated based on the data from Tomida et al. [11] and Chai et al. [12]. In addition, the pressure cell gives a good measurement at shear rate of 500 1/s. It indicates that shear rate up to 500 1/s does not cause any flow instabilities in the pressure cell, and the measurement is reliable.

Figure 2 and Figure 3 illustrate the viscosity of the toluene/crude oil mixture at various shear rates. The measurements at atmospheric pressure represent the viscosities of the diluted crude oils 
without $\mathrm{CO}_{2}$ dissolved at $25{ }^{\circ} \mathrm{C}$. The horizontal line demonstrates that the viscosities of both diluted crude oils are independent of shear rate, i.e. both samples behave as a Newtonian fluid. When the pressure increases, more and more $\mathrm{CO}_{2}$ dissolves into the crude oil and reduces the mixture viscosity significantly. However the addition of $\mathrm{CO}_{2}$ does not cause a change from Newtonian behavior, as the viscosity is constant for various shear rates at a specific pressure level. Therefore, although the dissolved $\mathrm{CO}_{2}$ could cause the precipitation of asphaltene, the dispersed particles do not appear to form an interacting network with each other for these crude oil mixtures.

Figure 4 summarizes the viscosity measurements at different pressures for the $\mathrm{CO}_{2}$ saturated mixtures of a crude oil sample at two different dilutions. The dissolved $\mathrm{CO}_{2}$ causes the diluted crude oil mixtures to have an exponential decrease of viscosity with pressures up to about 50 bar, and then the viscosities increase very slightly with pressure. We believe this change of pressure dependence of the viscosity is a consequence of the phase behavior change for the $\mathrm{CO}_{2}$ and crude oil mixtures.

As shown in Figure 5, when the pressure approaches 50 bar, a large amount of $\mathrm{CO}_{2}$ has been injected into the vessel for a small increase of pressure. We have a Liquid-Vapor (L-V) system at pressures below 50 bar consisting of a $\mathrm{CO}_{2}$ rich vapor phase and an oil rich liquid phase. Although the saturation point of pure $\mathrm{CO}_{2}$ at $25^{\circ} \mathrm{C}$ is $64 \mathrm{bar}$, when the pressure approaches $50 \mathrm{bar}$, a second liquid phase is generated. In this system three phases occur - an oil rich liquid, a $\mathrm{CO}_{2}$ rich liquid mixed with light hydrocarbons extracted from the crude oil, and a $\mathrm{CO}_{2}$ rich vapor - a LiquidLiquid-Vapor (L-L-V) system. The $\mathrm{CO}_{2}$ - rich liquid phase requires a large amount of $\mathrm{CO}_{2}$ and causes the jump in Figure 5 when the pressure is close to 50 bar. When the pressure is beyond the saturation point of $\mathrm{CO}_{2}, 64$ bar, the $\mathrm{CO}_{2}$ is in the liquid phase and we have a Liquid-Liquid (L-L) 
system. The phase change phenomena mentioned above have also been reported by Orr et al. in their study of the phase behavior of $\mathrm{CO}_{2}$ with crude oil and with alkanes [13].

As mentioned in the literature, in the L-L-V phase, the extracted light hydrocarbons significantly increase the viscosity of the $\mathrm{CO}_{2}$ - rich liquid phase, while the $\mathrm{CO}_{2}$ dissolved reduces the viscosity of the oil rich phase [13]. Therefore, at 60 bar the viscosity of the resulting mixture of these two liquid phases no longer follows the exponential decrease of the mixture viscosity with pressure increase, but decreases only slightly compared to the previous point which is for a mixture with a $\mathrm{L}-\mathrm{V}$ phase. When the pressure is above the saturation point of $\mathrm{CO}_{2}$, the viscosity measured is for a L-L system, and increases at higher pressure.

\section{Correlations}

As discussed above, in the $\mathrm{L}-\mathrm{V}$ region where the pressure is less than 50 bar, the viscosity of the $\mathrm{CO}_{2}$ and diluted crude oil mixture reduces exponentially with pressure increase, because of $\mathrm{CO}_{2}$ dissolution. The pressure dependence can be described by

$$
\ln \left(\eta_{\mathrm{m}}\right)=a_{1} P+b_{1} @ P \leq 50 \text { bar }
$$

When the pressure is above 50 bar, giving rise to the L-L-V or L-L region, the viscosity of the mixture increases linearly with pressure:

$$
\eta_{\mathrm{m}}=a_{2} P+b_{2} @ P>50 \mathrm{bar}
$$

The values of the fitting parameters $a_{1}, b_{1}, a_{2}$, and $b_{2}$ are summarized in Table 3.

Additionally, in the $\mathrm{L}-\mathrm{V}$ region, the amount of $\mathrm{CO}_{2}$ injected into the mixer corresponds to the amount of $\mathrm{CO}_{2}$ dissolved in the diluted crude oil, since it is only way the $\mathrm{CO}_{2}$ can be consumed. 
Given that the amount of diluted crude oil loaded in the mixer is known, one can calculate the mass fraction of $\mathrm{CO}_{2}$ in the mixture, which is in fact the solubility of $\mathrm{CO}_{2}$ in the diluted crude oil. Therefore, the viscosity data and $\mathrm{CO}_{2}$ solubility at pressures lower than 50 bar have been correlated using the equation reported by Shu [14], which is a modified version of the classic Arrhenius expression ,

$$
\ln \left(\eta_{\mathrm{m}}\right)=X_{\mathrm{o}} \ln \left(\eta_{\mathrm{o}}\right)+X_{\mathrm{s}} \ln \left(\eta_{\mathrm{s}}\right)
$$

with

$$
\begin{gathered}
X_{s}=\frac{v_{s}}{\alpha v_{o}+v_{s}} \\
X_{o}=1-X_{s}
\end{gathered}
$$

where $v$ is volume fraction and the subscripts $\mathrm{o}, \mathrm{s}$, and $\mathrm{m}$ stand for diluted crude oil, $\mathrm{CO}_{2}$ and $\mathrm{CO}_{2}$ /diluted crude oil mixture, respectively. The pressure dependence of the diluted crude oil viscosity was not significant and was ignored. The viscosity of pure $\mathrm{CO}_{2}$ as a function of temperature and pressure was obtained from the NIST Chemistry WebBook [9].

The empirical parameter $\alpha$ in Equation (4) has to be determined by fitting data via a nonlinear optimization that minimizes the absolute average relative deviation, $\Delta_{\mathrm{AAD}, X}$

$$
\Delta_{\mathrm{AAD}, X}=\frac{1}{N} \sum_{i=1}^{N}\left(\frac{\left|X_{i}-X_{i, \mathrm{fit}}\right|}{X_{i}}\right)
$$

where $X_{i}$ is the experimental data, $X_{i}$,fit calculated from the correlation applied at the same conditions, and $N$ the total number of points. The resulting values of the parameter $\alpha$ for the 
diluted crude oils are given in Table 3. The correlation results are illustrated in Figure 6, and the $\Delta_{\mathrm{AAD}, X}$ for both diluted crude oils is $1 \%$.

\section{Conclusions}

According to our observations, for our particular diluted crude oil samples, $\mathrm{CO}_{2}$ dissolution does not cause non-Newtonian behavior for $\mathrm{CO}_{2}$ - diluted crude oil mixtures. In the $\mathrm{L}-\mathrm{V}$ region the dissolved $\mathrm{CO}_{2}$ causes an exponential decrease in the viscosity of the $\mathrm{L}$ phase with increasing pressure. When the system reaches the L-L-V region, increasing pressure further results in a slight linear increase in the viscosity of the densest phase. The system reaches the L-L region at a pressure lower than the pure $\mathrm{CO}_{2}$ vapor-liquid saturation pressure. In addition, the modified Arrhenius equation developed by Lederer provides a good correlation between the viscosity data and the amount of dissolved $\mathrm{CO}_{2}$ in the $\mathrm{L}-\mathrm{V}$ region.

\section{FIGURES}

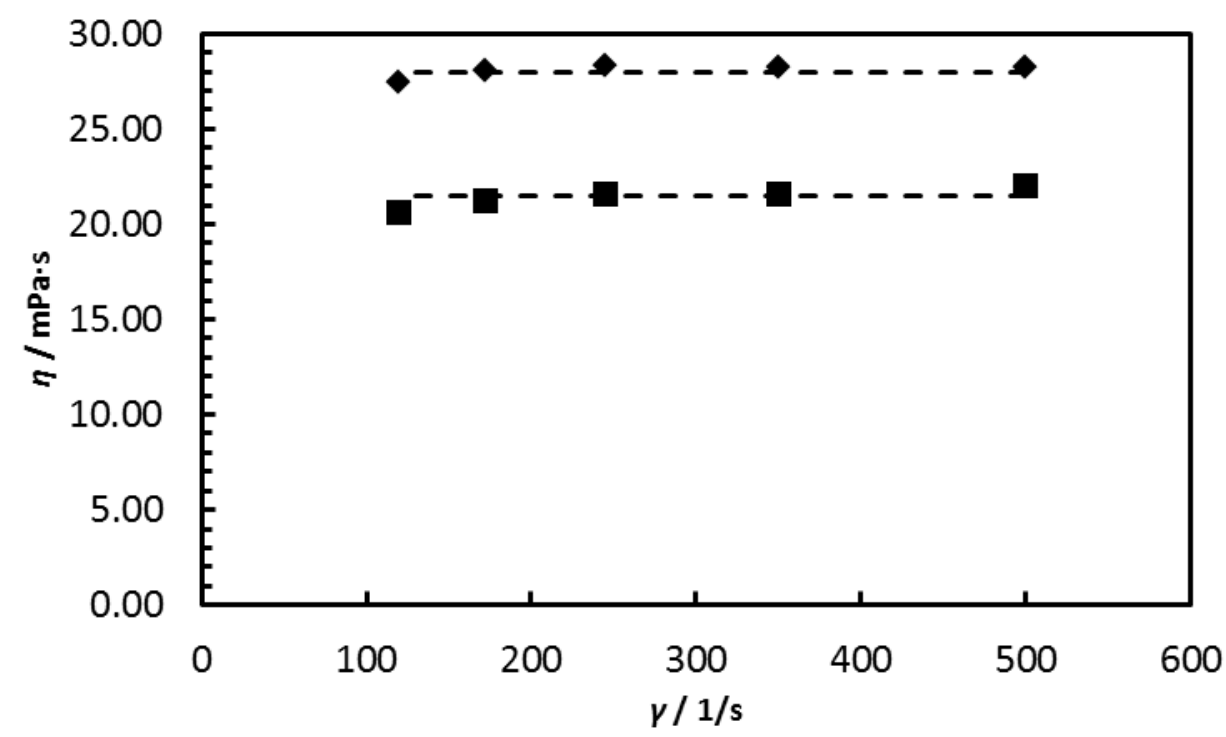

Figure 1. Comparison between the viscosity measurements by the circulation system and the literature values of squalane and its mixture with $\mathrm{CO}_{2}$ at $25^{\circ} \mathrm{C}$. $\diamond, 1$ bar, pure squalane; $\square, 4.3 \mathrm{bar}$, squalane saturated with $\mathrm{CO}_{2}$; --, reference value. 


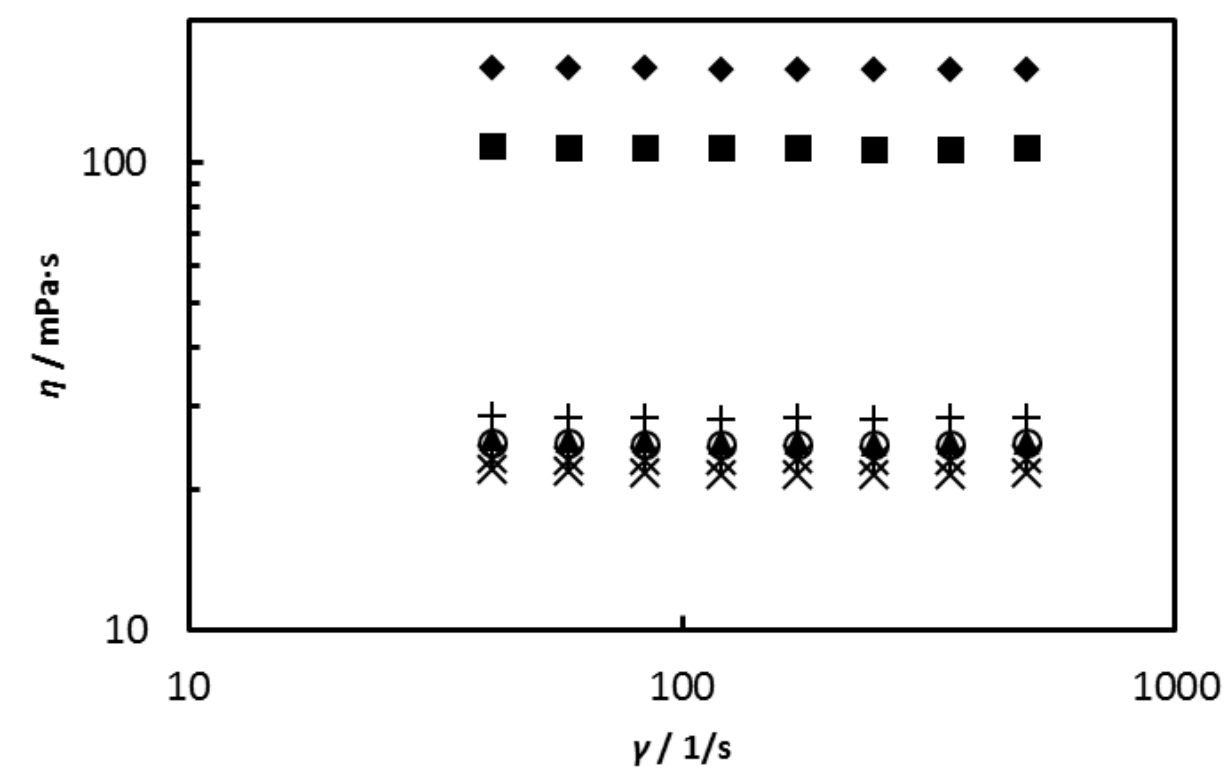

Figure 2. Viscosity measurement for diluted crude oil 1 with $\mathrm{CO}_{2}$ at $25{ }^{\circ} \mathrm{C}$ and various shear rates. $\bullet, 1 \mathrm{bar} ; \square, 10 \mathrm{bar} ; \Delta$, 40 bar; $\times, 60$ bar; $*, 100$ bar; $\bigcirc, 140$ bar;,+ 220 bar.

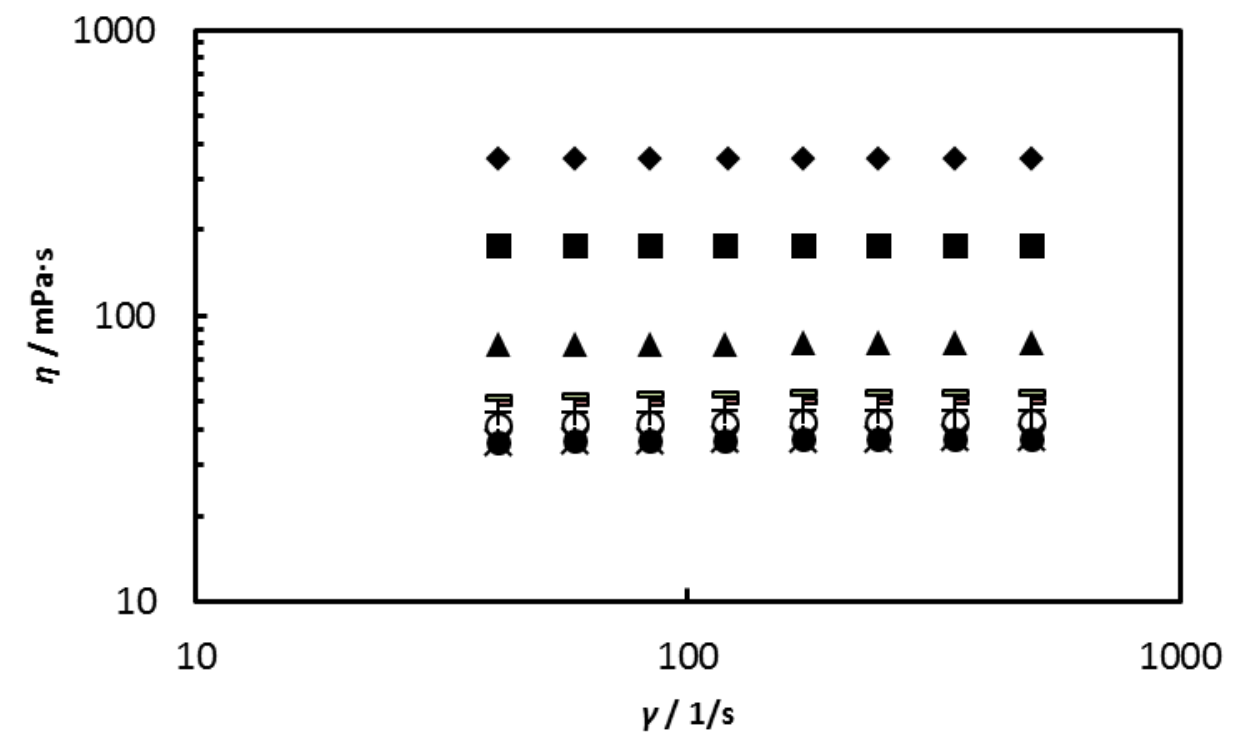

Figure 3. Viscosity measurement for diluted crude oil 2 with $\mathrm{CO}_{2}$ at $25{ }^{\circ} \mathrm{C}$ and various shear rates. $\diamond, 1 \mathrm{bar} ; \boldsymbol{\square}, 15 \mathrm{bar} ; \Delta$, 30 bar; $\bullet, 45$ bar; $*, 60$ bar; $\bigcirc, 100$ bar;,+ 140 bar; $\triangle$, 180 bar; $\diamond, 220$ bar. 


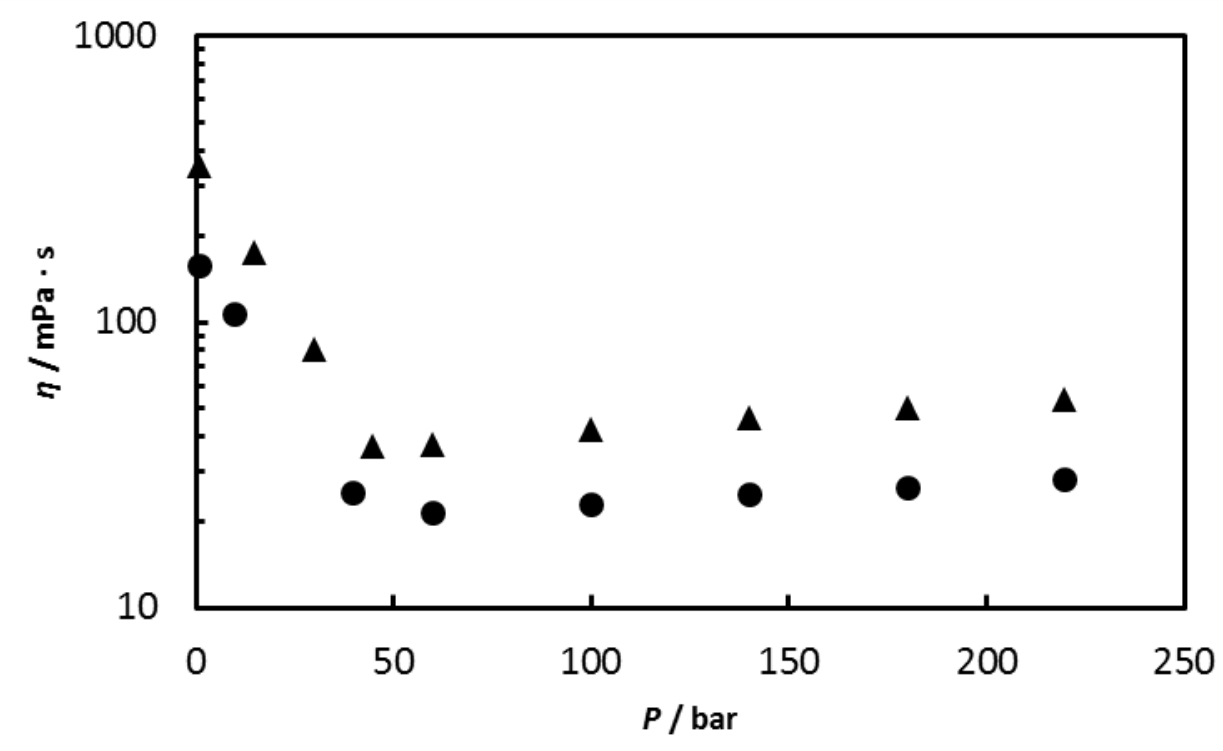

Figure 4. Viscosity measurement for diluted crude oil 1 and 2 with $\mathrm{CO}_{2}$ at various pressures at $25^{\circ} \mathrm{C}$. $\bullet$, diluted crude oil 1; $\boldsymbol{\Delta}$, diluted crude oil 2.

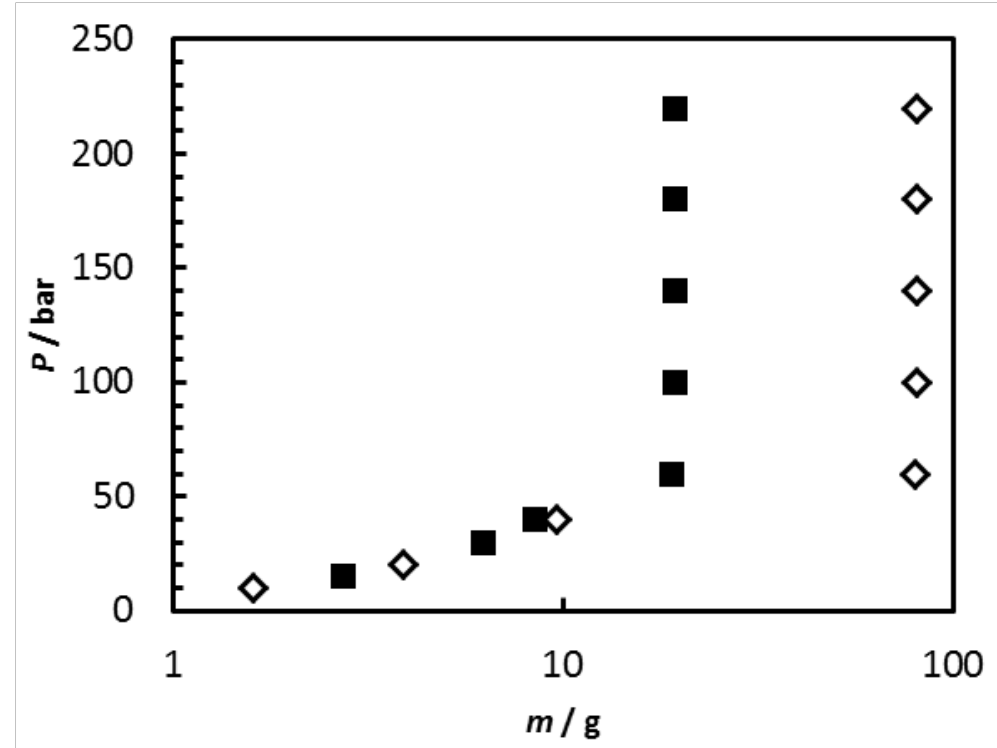

Figure 5. The mass of $\mathrm{CO}_{2}$ injected into the mixer at difference pressure and $25^{\circ} \mathrm{C} . \diamond$, diluted crude oil 1; $\mathbf{\square}$, diluted crude oil 2 


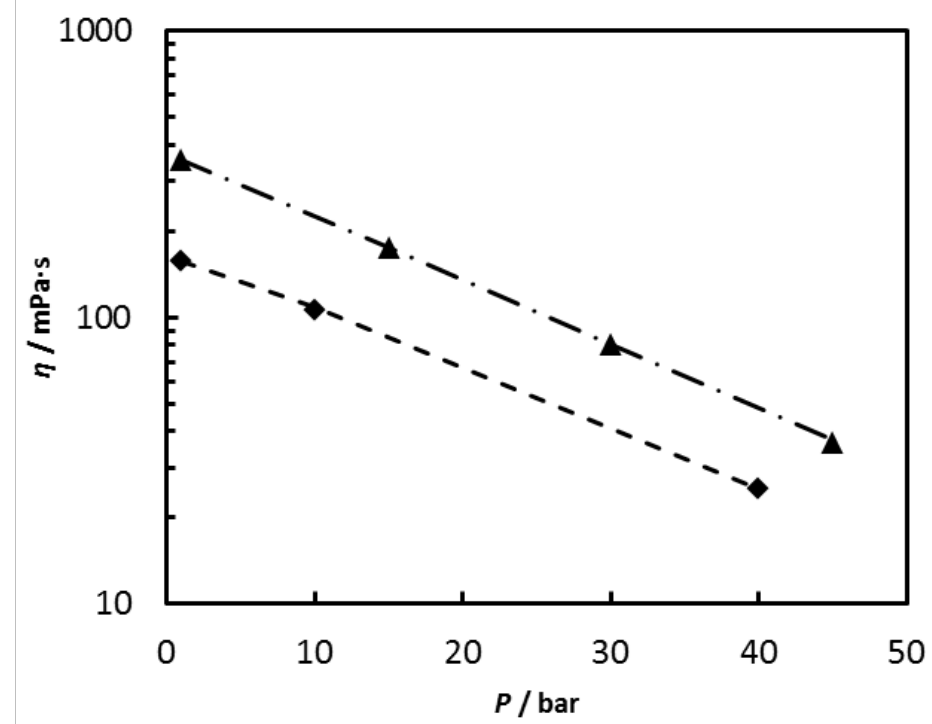

Figure 6. The comparison between the correlation results from Equation Error! Reference source not found. and measurement. $\downarrow$, viscosity measurement for diluted crude oil 1 ; $\Delta$, viscosity measurement for diluted crude oil 2 ; -- , correlation for diluted crude oil 1 ; - •, correlation for diluted crude oil 2.

\section{SCHEMES}

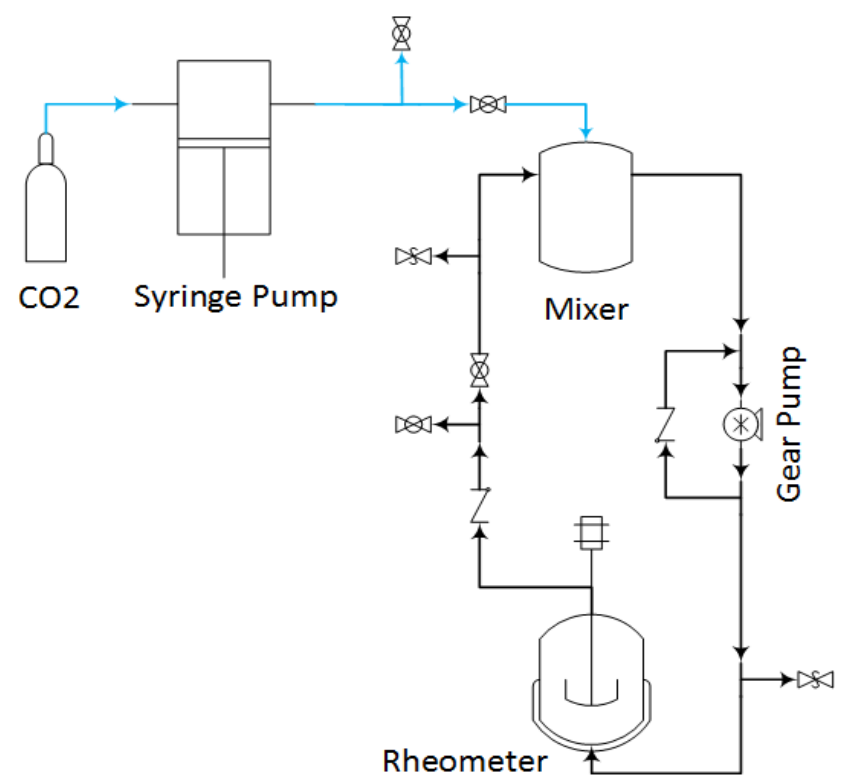

Scheme 1. The scheme of the circulation system to measure the viscosity of $\mathrm{CO}_{2}$ saturated crude oils. The blue line in the scheme represents $\mathrm{CO}_{2}$ flow, while black one the crude oil mixtures. 


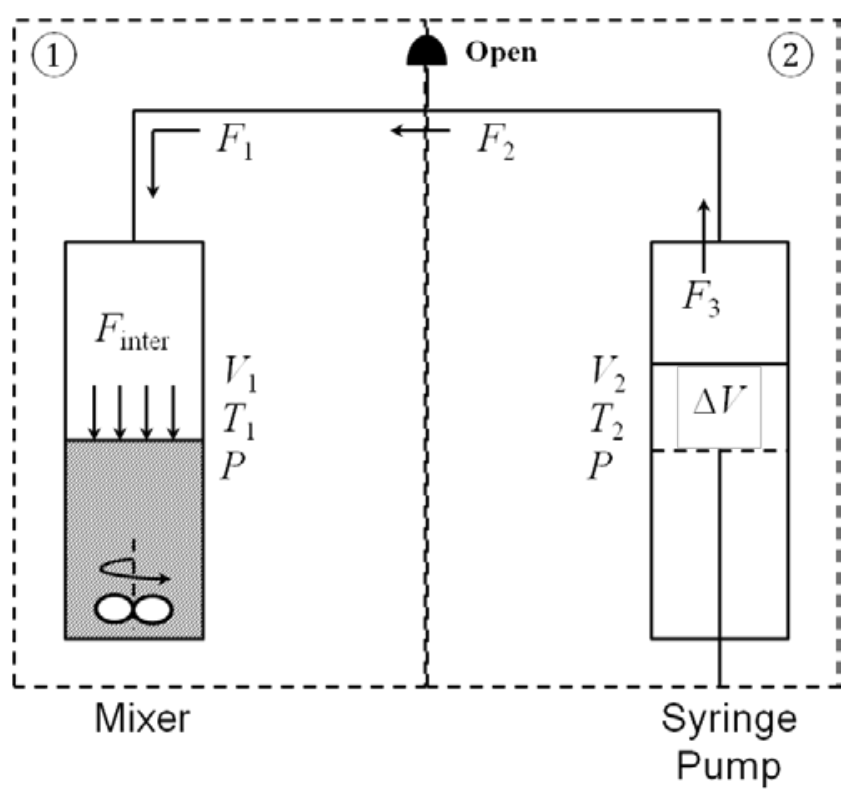

Scheme 2. The scheme showing the principle of measuring the amount of CO2 injected into the mixer. $F_{i}$ is the flowrate of $\mathrm{CO}_{2}$ at position $i, \Delta V$ the volume change in the syringe pump. $F_{1}=F_{2}=F_{3}=F_{\text {inlet }}$ when the syringe pump is set to operate at constant pressure mode.

TABLES.

Table 1. The characteristics of the crude oil used in this study

\begin{tabular}{lr}
\hline \multicolumn{1}{c}{ Characteristics } & \multicolumn{2}{c}{ Value } \\
\hline \hline API Gravity & 9.28 \\
Barrel Factor (bbl/t) & 6.27 \\
Total Sulphur (\% wt) & 3.35 \\
Reid Vapour Pressure (kPa) & 1 \\
Pour Point $\left({ }^{\circ} \mathrm{C}\right)$ & 24 \\
Existing $\mathrm{H}_{2} \mathrm{~S}$ Content $(\mathrm{ppm})$ & - \\
Potential $\mathrm{H}_{2} \mathrm{~S}$ Content $(\mathrm{ppm})$ & 115 \\
Potential $\mathrm{HCl}$ Content $(\mathrm{ppm})$ & - \\
Calc. Gross Cal. Value $(\mathrm{kJ} / \mathrm{kg})$ & 41855 \\
\hline
\end{tabular}

Table 2. The composition of the diluted crude oil studied.

\begin{tabular}{cc}
\hline Component & Composition \\
\hline \hline Diluted crude oil 1 & 80 w\% Crude oil + 20 w\% Toluene \\
Diluted crude oil 2 & 85 w\% Crude oil + 15 w\% Toluene \\
\hline
\end{tabular}


Table 3. The value of fitting parameters in Equation (1), (2) and (4)

\begin{tabular}{crrrrr}
\hline Component & \multicolumn{1}{c}{$a_{1}$} & \multicolumn{1}{c}{$b_{1}$} & \multicolumn{1}{c}{$a_{2}$} & \multicolumn{1}{c}{$b_{2}$} & $\alpha$ \\
\hline \hline Diluted crude oil 1 & -0.047 & 5.123 & -0.052 & 5.930 & 188.648 \\
Diluted crude oil 2 & 0.043 & 18.833 & 0.103 & 31.448 & 174.302 \\
\hline
\end{tabular}

\section{AUTHOR INFORMATION}

\section{Corresponding Author}

* E-mail: e.boek@imperial.ac.uk.

\section{Funding Sources}

Any funds used to support the research of the manuscript should be placed here (per journal style).

\section{ACKNOWLEDGMENT}

We gratefully acknowledge funding from the Qatar Carbonates and Carbon Storage Research Centre (QCCSRC), provided jointly by Qatar Petroleum, Shell, and Qatar Science and Technology Park. We thank Frans van den Berg (Shell Global Solutions, Amsterdam, Netherlands) for providing the crude oil sample.

\section{REFERENCES}

1. NRC, Advancing the Science of Climate Change. 2010: The National Academies Press.

2. Srivastava, R.K., S.S. Huang, and M.Z. Dong, Asphaltene deposition during CO2 flooding. Spe Production \& Facilities, 1999. 14(4): p. 235-245.

3. Barnes, H.A.H.J.F.W.K., An introduction to rheology. 1989, Amsterdam; New York: Elsevier : Distributors for the U.S. and Canada, Elsevier Science Pub. Co.

4. Kariznovi, M., H. Nourozieh, and J. Abedi, Experimental apparatus for phase behavior study of solvent-bitumen systems: A critical review and design of a new apparatus. Fuel, 2011. 90(2): p. 536-546.

5. Behzadfar, E. and S.G. Hatzikiriakos, Rheology of bitumen: Effects of temperature, pressure, CO2 concentration and shear rate. Fuel, 2014. 116(0): p. 578-587. 
6. Seifried, C.M., J. Crawshaw, and E.S. Boek, Kinetics of Asphaltene Aggregation in Crude Oil Studied by Confocal Laser-Scanning Microscopy. Energy \& Fuels, 2013. 27(4): p. 1865-1872.

7. Arnolds, O., Rheology at high pressure setup and performance of the 1000 bar pressure cell. 2013, Anton Paar.

8. McManamey, W.J. and J.M. Woollen, The diffusivity of carbon dioxide in some organic liquids at $25^{\circ}$ and $50^{\circ} \mathrm{C}$. AIChE Journal, 1973. 19(3): p. 667-669.

9. $\quad$ Linstrom, P.J. and E. W.G. Mallard, NIST Chemistry WebBook, NIST Standard Reference Database Number 69. 2014: National Institute of Standards and Technology.

10. Ciotta, F., et al., Viscosity and Density of Carbon Dioxide + 2,6,10,15,19,23-

Hexamethyltetracosane (Squalane)†. Journal of Chemical \& Engineering Data, 2009. 54(9): p. 2436-2443.

11. Tomida, D., A. Kumagai, and C. Yokoyama, Viscosity Measurements and Correlation of the Squalane + CO2 Mixture. International Journal of Thermophysics, 2007. 28(1): p. 133-145.

12. Chai, C.-P. and M.E. Paulaitis, Gas solubilities of carbon dioxide in heavy hydrocarbons. Journal of Chemical \& Engineering Data, 1981. 26(3): p. 277-279.

13. Orr, F.M., A.D. Yu, and C.L. Lien, Phase-Behavior of Co2 and Crude-Oil in LowTemperature Reservoirs. Society of Petroleum Engineers Journal, 1981. 21(4): p. 480492.

14. Shu, W.R., A Viscosity Correlation for Mixtures of Heavy Oil, Bitumen, and Petroleum Fractions. Society of Petroleum Engineers Journal, 1984. 24(3): p. 277-282. 